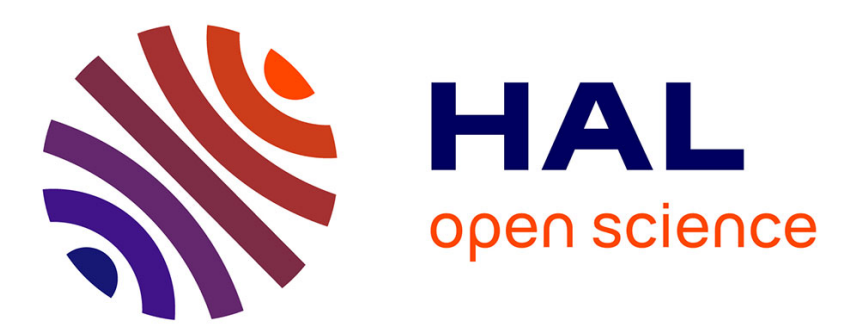

\title{
Rupture limit evaluation of human cerebral aneurysms wall: Experimental study
}

Hervé Brunel, Dominique Ambard, H Dufour, P.H. Roche, Vincent Costalat, Franck Jourdan

\section{> To cite this version:}

Hervé Brunel, Dominique Ambard, H Dufour, P.H. Roche, Vincent Costalat, et al.. Rupture limit evaluation of human cerebral aneurysms wall: Experimental study. Journal of Biomechanics, 2018, 77, pp.76-82. 10.1016/j.jbiomech.2018.06.016 . hal-01863317

\section{HAL Id: hal-01863317 https://hal.science/hal-01863317}

Submitted on 28 Aug 2018

HAL is a multi-disciplinary open access archive for the deposit and dissemination of scientific research documents, whether they are published or not. The documents may come from teaching and research institutions in France or abroad, or from public or private research centers.
L'archive ouverte pluridisciplinaire HAL, est destinée au dépôt et à la diffusion de documents scientifiques de niveau recherche, publiés ou non, émanant des établissements d'enseignement et de recherche français ou étrangers, des laboratoires publics ou privés. 


\title{
Rupture limit evaluation of human cerebral aneurysms wall: experimental study
}

\author{
H. Brunel ${ }^{\mathrm{a}, \mathrm{b}}$, D. Ambard ${ }^{\mathrm{a}}$, H. Dufour ${ }^{\mathrm{b}}$, P.H. Roche ${ }^{\mathrm{b}}$, V. Costalat $^{\mathrm{c}}$, and F. Jourdan ${ }^{\mathrm{a} *}$ \\ ${ }^{a}$ LMGC, Univ. Montpellier, CNRS, France; ${ }^{b} \mathrm{CHU}$-AMU Marseille, France; ${ }^{c} \mathrm{CHU}$ Montpellier, France
}

\begin{abstract}
Background and purpose

Rupture risk of intracranial aneurysms is a major issue for public healthcare. A way to obtain an individual rupture risk assessment is a main objective of many research teams in the world. For many years, we have investigated the relationship between the mechanical properties of aneurysm wall tissues and the rupture risk. In this work, we try to go further and investigate rupture limit values.
\end{abstract}

\section{Methods}

Following surgical clipping, a specific conservation protocol was applied to aneurysmal tissues in order to preserve their mechanical properties. Thirty-nine intracranial aneurysms ( 27 females, 12 males) were tested using a uniaxial tensile test machine under physiological conditions, temperature, and saline isotonic solution. These represented 24 unruptured and 15 ruptured aneurysms. Stress/strain curves were then obtained for each sample, and a fitting algorithm was applied following a Yeoh hyperelastic model with 2 parameters. Moreover, uniaxial tensile tests were conducted until rupture of samples to obtain values of stress and strain rupture limit.

\section{Results}

The significant parameter a $C_{2}$ of the hyperelastic Yeoh model, allowed us to classify samples' rigidity following the terminology we adopted in previous papers (Costalat 2011, Sanchez 2013): Soft, Stiff and Intermediate. Moreover, strain/stress rupture limit values were gathered and analyzed thanks to the tissue rigidity, the status of the aneurysm (initially ruptured or unruptured) and the gender of the patient.

\section{Conclusion}

Strain rupture limit was found quite stable around $20 \%$ and seems not to be correlated with the status of the aneurysm (initially ruptured or unruptured), neither with the gender of the patient. However, stretch and stress rupture limit seems not to be independent on the rigidity.

The study confirms that ruptured aneurysms mainly present a soft tissue and unruptured aneurysms present a stiff material.

Keywords

Intracranial aneurysm; Soft tissue; Hyperelastic material; Rupture limit; human specimen; Uniaxial traction test

\section{Introduction}

Hemorrhage stroke is a major issue for public healthcare. Approximately $12 \%$ of patients die before receiving medical attention, $40 \%$ of hospitalized patients die within one month after the accident, and more than one third of those who survive have major neurological deficits. The prevalence of intracranial aneurysms in the general population, as reported by (Wardlaw and White, 2000), ranges between 3\% and 6.6\%. Fortunately, very few aneurysms rupture. The incidence of ruptured aneurysms is approximately $0.5 \%$ per year. However, when a patient knows he has a "bomb" in his head, he is stressed and wants to be treated. But endovascular treatment of unruptured aneurysms, which is the safest treatment, is not without risk and has about $1 \%$ mortality rate (Sluzewski et al., 2001). Unruptured intracranial aneurysms therefore represent a dilemma for the physicians. The risk of aneurysm rupture with respect to its natural history has to be carefully balanced against the risk of morbidity and mortality from an endovascular or surgical repair. 
Many factors are available to help decisions for surgery, like the size of the sac and its location in the Circle of Willis (ISUIAI, 1998). Other parameters, such as irregular aneurysm shape and, in particular, the presence of blebs (Asari and Ohmoto, 1993 and Wiebers et al., 1987) are recognized as high risk factors.

In 2011 (Costalat et al. 2011), we proposed an additional indicator base on the relationship between the mechanical properties of aneurysm wall tissues and the rupture risk. First conclusions suggested that the softer tissue is, the higher rupture risk is.

The present study aims to confirm these results, initiates with only 16 samples, studying 24 more aneurysms, and tries to go further investigating rupture limit values of aneurysmal tissues.

\section{Materials and methods}

\subsection{Patients and clinical data}

A total of sixty-three patients treated for ruptured or unruptured aneurysms by surgical clipping were recruited by four French neurosurgical teams. The research study protocol was approved by the local ethical committee in each center. A consent form was signed by patients with normal neurological status, or by the relatives in all other cases. For each patient, clinical, and radiological informations were collected concerning age, gender, aneurysm status (ruptured/unruptured), size (measured from the dome of the aneurysm and the neck represented by the communication of the aneurysm with the parent artery), the "dome to neck" ratio (aneurysm size/neck length), location on the Willis circle, morphological evaluation (classified "simple shaped" for a regular unilobulated aneurysm and "complex shaped" for a multilobulated and irregular aneurysm), as well as documented rupture risk factors; multiple aneurysms, previous ruptured aneurysm, positive family history of ruptured intracranial aneurysm, autosomal dominant polycystic kidney disease, hypertension, alcohol and tobacco. A possible mycotic intracranial aneurysm etiology was considered an exclusion criterion, as well as any previous history of endocarditis or inflammatory disease. All documented risk factors were then recorded in order to be related to the biomechanical behavior of each aneurysm.

\subsection{Biomechanical testing methodology}

Immediately after resection, each aneurysm wall was progressively frozen respecting a procedure described in (Costalat et al., 2011). The resected aneurysm was initially inserted in a tube containing a Ringer lactate, $10 \%$ DMSO solution. This first tube was then placed in a larger second one containing isopropanol. This combination of the two tubes was placed in a freezer $\left(-80^{\circ} \mathrm{C}\right)$. The sample was progressively frozen due to the surrounding isopropanol solution in order to maintain its biomechanical properties.

One hour before mechanical testing, aneurysm samples were thawed at ambient temperature. Then a regular rectangular piece was dissected from the aneurysm preserving maximum length. This was a delicate point due to the small size of the samples. Many of them were lost during this cutting.

Once cut, a uniaxial stretch test was carried out on the sample within a warmed $\left(37^{\circ} \mathrm{C}\right)$ physiological liquid in order to simulate in vivo conditions. This testing device was composed of a Texture Analyzer (TA-XT2, Stable Microsystems, UK) with a $50 \mathrm{~N}$ load cell. Aneurysm strips were fixed by glue on each extremity to aluminum grips.

Two digital video cameras, placed in two orthogonal directions, recorded the mechanical tests (see Figure 1).

The uniaxial stretch tests consisted of a series of increasing load steps until rupture of the sample.

- $\quad$ For the first load step the sample was stretched by about $10 \%$ of its initial length, then unloaded and that was repeated five times. This $10 \%$ value was initially calculated by (Karmonik et al. 2010) in an in vivo wall motion MRI study of 7 aneurysms. In accordance to standard mechanical testing protocol for biological tissue, the specimens were first preconditioned (Holzapfel and Ogden, 2009) during the first four cycles. The extension rate was $0.01 \mathrm{~mm} / \mathrm{s}$ and the tension load was recorded every $0.01 \mathrm{~s}$. Velocity of the solicitations was small enough to not consider viscous phenomena. A baseline tension of $0 \mathrm{~N}$ was applied to the strip before starting each test.

- For the next load steps, the stretch was increased by $10 \%$ with the same number of loading/unloading cycles, under the same velocity conditions. 
- $\quad$ Loads were increased until rupture of the sample occurred.

During the tests, the two subset cameras were used to record the displacement of the sample. These images (resolution of $4 \mu \mathrm{m} / \mathrm{pixel}$ ) allowed to determine the exact dimensions (width, length and thickness) of the strips. A Force/Displacement graph was obtained from each sample tested (see Figure 2).

\subsection{Data post-processing}

\subsubsection{Mechanical parameter identifications}

Only the measurements from the last elongation of load step 1 were used to obtain more realistic mechanical characterization of the data. Note, however, that except for the very first cycle, the force/displacement graph was roughly cycle independent. In order to identify the parameters of an equivalent hyperelastic model, the force/displacement graph described above was converted into a strain/stress graph. For this calculation, the length, thickness and width of each strip were considered. A baseline for this aneurysmal strip dimensions were obtained at 0-Newton traction in the third cycle of each test. Using the assumption that the specimen was subjected to a uniform traction, the engineering stress, noted $\Pi$, was computed, and the engineering strain, noted $\varepsilon$, registered.

During the cycles, some permanent deformations in the traction phase were observed causing slight compressions of the sample in the rest phase. This is reflected by the negative values of the curve origin and is in accordance to the elasto-plastic behavior of the tissue. Since we consider a hyperelastic model to represent the tissue, the plastic effects cannot be represented and only the positive part of the curve was used to identify material behavior.

Once the strain/stress graph was obtained, we proceeded to a curve fitting using a Sequential Least Squares Programming algorithm in order to determine the corresponding hyperelastic model and its coefficients. In our cases, the best match was obtained with an incompressible Yeoh model with 2 parameters. Let $F$ be the measured force, $S_{0}$ the initial section and $\lambda=1+\varepsilon$ the elongation of the sample, the behavior law is given by the following equation:

$$
\Pi=\frac{F}{S_{0}}=2\left(\lambda-\lambda^{-2}\right)\left(C_{1}+2 C_{2}\left(\lambda^{2}+2 \lambda^{-1}-3\right)\right)
$$

where mechanical parameters $C_{1}$ and $C_{2}$ have to be identified.

\subsubsection{Rupture limit identifications}

Hemorrhage occurs when the aneurysmal wall ruptures, but this rupture is rather a local cracking than a total and entire tearing. In majority of the ruptures we observed in-vitro, the sample was not cut into two distinct pieces, but there was an abrupt loss of resistance. The specimens stayed in one piece held by undamaged fibers. Hence, we decided that the rupture limit would be given by the point of maximum stress.

An example of strain/stress curve, with visible rupture, is given in Figure 3. This figure represents the last load for the aneurysm of Figure 2, but expressed with stress and strain variables.

For each sample the limit of stress $\Pi_{r}$ and elongation $\lambda_{r}$ values were collected.

\section{Results}

We initially collected 63 specimens, but were able to test only 39. It was mainly because of the cutting of the samples due to their small size. The second cause of the losses is related to the positioning of the samples in the tensile machine. We broke a few cases during the procedure. All results are gathered in table 1. It summarizes clinical, anatomical and biomechanical data of the 39 cases tested (A tiny fraction of the information is missing). 


\subsection{Material parameters values}

For this type of behavior law (Yeoh hyperelastic model), parameter $C_{1}$ is related to the Young modulus $E$, which is the slope at origin $(\lambda=1)$ of the function $\Pi(\lambda)$. It could be easily demonstrated that $C_{1}$ is equal to $E / 6$. Parameter $C_{2}$ is representative of the curvature of the function $\Pi(\lambda)$. The larger the parameter $C_{2}$ is, the higher rigidity of the material is.

After the identification procedure, we gathered the values of parameters $C_{1}$ and $C_{2}$ respectively in the graphs Figure 4 and Figure 5. These values are sorted according to the aneurysm status before surgery (ruptured (red points) or unruptured (green points)) and to the gender (female (circles) or male (squares)). On average, unruptured aneurysms are stiffer than ruptured ones. Indeed, the average value for $C_{1}$ is $0.07 \mathrm{MPa}$ for ruptured and $0.12 \mathrm{MPa}$ for unruptured aneurysms. The same trend is observed for parameter $\mathrm{C} 2$ : the average value is 2.1 MPa for ruptured and 6.8 MPa for unruptured. But, the results show also that some unruptured aneurysms have soft material properties. For both parameters, there seems to be an upper limit for ruptured aneurysms: $0.2 \mathrm{MPa}$ for $C_{1}$ and $10 \mathrm{MPa}$ for $C_{2}$.

Moreover, we noticed that all ruptured aneurysms have a $C_{2}$ lower than $3.7 \mathrm{MPa}$, except one which is equal to 7 MPa. Then we stratified aneurysms in 3 categories:

- Soft tissues are those having a $C_{2}$ lower than $3.7 \mathrm{MPa}$

- Intermediates tissues are those having a $C_{2}$ between $3.7 \mathrm{MPa}$ and $7 \mathrm{MPa}$

- Stiff tissues are those having a $C_{2}$ greater than $7 \mathrm{MPa}$

Concerning the influence of the gender on material parameters, the graphs in Figure 4 and Figure 5 do not show a significant dependence. Aneurysmal tissues from males seem not to be stiffer than those of females and vice versa (p-value $=0.79$ for $C_{1}$ and 0.39 for $C_{2}$ ).

\subsection{Rupture limit values}

For each specimen, the stress and stretch rupture limit have been identified and sorted by different criteria: gender, status (ruptured/unruptured) and rigidity (soft/intermediate/stiff). Results are presented in the graphs Figure 6 and Figure 7. Symbols and color codes are the same as in the previous paragraph. Neither correlation between the previous specific criteria and the stress was found, nor with the stretch. Stretch rupture limit does not depend on the gender ( $\mathrm{p}$-value $=0.22)$, nor on the status ( $\mathrm{p}$-value $=0.78$ ). Stress rupture limit also does not depend on gender $(\mathrm{p}$-value $=0.38)$. However, stretch and stress rupture limit seems not to be independent on the rigidity (respectively $\mathrm{p}$-value $=0.006$ and $\mathrm{p}$-value $=0.04$ )

Furthermore, when reporting the engineering stress and the engineering strain (instead of the stretch) limit in a same graph (Figure 8) we clearly see that a notion of strain limit is more relevant than one of stress limit. The average value for the strain limit is about 0.2 (20\% of deformation), with a standard deviation of 0.06 while the average value for the engineering stress limit $\Pi_{r}$ is about $0.38 \mathrm{MPa}$, with a standard deviation of $0.24 \mathrm{MPa}$.

\section{Limitations and discussion}

Several points about experimental results and limitations must be discussed.

\subsection{Result analysis}

Almost certainly the physicians made the right choice in treating the unruptured aneurysms having a $C_{2}$ lower than 3.7 MPa (soft tissues). In a general manner, both soft and intermediate tissues had a risk of rupture, because we found a ruptured aneurysm with a $C_{2}$ equals to $7 \mathrm{MPa}$. At this time, only stiff tissues ( $C_{2}>7 \mathrm{MPa}$ ) seem to be safe.

In terms of comparisons, we are able to compare parameter $C_{1}$ with those obtained in the literature. In (Valencia et al. 2015), they extracted from a Mooney-Rivlin hyperelastic model, an average value of parameters $C_{01}+C_{10}$, 
equivalent to our $C_{1}$, of about $0.17 \mathrm{MPa}$, while in (Toth et al. 2007) they found $0.12 \mathrm{MPa}$. They are of same order than our average value for $C_{1}: 0.11 \mathrm{MPa}$. Unfortunately, we cannot compare $C_{2}$, which is however the most significant.

Beyond that, our results highlighted an average rupture limit for strain of about 20\%. Already, in 1989 Steiger and co-authors (Steiger et al, 1989), presented rupture limit value for strain. Only 7 aneurysms were tested for an average strain rupture limit of 37\%. More recently, works of (Cebral et al., 2015) and (Valencia et al., 2015), extracted also rupture limit values from their uniaxial traction tests. In both articles few samples were tested, due to the difficulty of getting aneurysms from surgery. Cebral and co-authors found an average value of $37 \%$ for a total of 8 unruptured aneurysms and compared the rupture limit values to those of control arteries in (Robertson et al., 2015). Valencia and co-authors, found an average value of 38\% for 6 samples. The difference between our results and those of the literature may come from several reasons. First, the testing protocol is mainly different, because in our study, the sample is immersed in a physiological liquid controlled in temperature at $37{ }^{\circ} \mathrm{C}$. The effect of the temperature is probably not negligible. Secondly, all our samples were initially frozen (as reported in (Masson et al. 2009), while in the other studies, they were tested without freezing in a maximum of $48 \mathrm{~h}$ after surgery. Finally, the total number of tested samples could also explain this difference. In a general manner, we think that in vivo rupture limit may be lower than $38 \%$, because a simple mechanical analysis on a hemispherical model of aneurysm, using the Laplace theory and assuming standard material thickness and radius values, shows that strains are about 2 or $3 \%$ in physiological conditions of pressure. Then, the pressure should be increased by almost a factor of 10 for reaching the values of measured rupture limits.

On the other hand, several authors (García-Herrera et al, 2012; Pichamuthu et al, 2013; Pham et al, 2013; Forsell et al, 2014) have investigated the uniaxial rupture properties of ATAAs (Ascending Thoracic Aortic Aneurysms). Works of Duprey and co-authors (Duprey et al, 2016) on ATAAs exhibit an average rupture limit value for strain of $69 \%$, which is different than our. This mismatch could be explained because pathologies are really different. ATAAs mainly concern old persons with stiff arterial properties due to the atheromatous process, while cerebral aneurysms occur more often in younger people.

All these observations go in the same direction. For a given arterial pressure, a soft tissue has a higher risk of rupture than a stiff one, because it has a larger deformation which tends to come closer to the strain rupture limit (20\%). Our study also confirms observations suggesting that big aneurysms are dangerous (Wiebers et al, 2003). Indeed, thanks to the Laplace theory, the larger the bending radius is, the higher the stress in the wall of the membrane (aneurysm wall) is. In big aneurysms, the strain would then be higher and closer to the rupture limit, than in a small aneurysm for a same arterial pressure. This phenomenon is worsened for soft tissues.

Finally, from a mechanical point of view, consideration of only the wall stiffness is not sufficient, the strain rupture limit must be taken into account too. Indeed, for the ruptured aneurysm having a $C_{2}$ equals to $7 \mathrm{MPa}$, we found a strain rupture limit equal to $10 \%$ (two times inferior of the average limit value). This aneurysm was the unique specimen from the posterior vertebrobasilar circulation we tested and it is well known that they are more dangerous at the same size than those located in other places (Wiebers et al, 2003). So, wall stiffness has to be considered in the light of the strain rupture limit. Moreover, with the same tissue (material properties) and at the same arterial pressure, the strain is higher if the thickness of the wall is smaller, which increases the risk of rupture.

Of course, all these values have to be considered carefully, even though we paid a lot of attention to measurements and in the control of results. Despite this, a security coefficient should be applied to these bounded values.

\subsection{Limitations}

Because of the surgical resection necessary to obtain these samples, only aneurysms easily and safely accessible were selected, introducing a potential selection bias. Hence, the MCA (Middle Cerebral Artery) location was over-represented in this study. There may be also a bias induced by the differences between cases with indication of surgical treatment compared to those indicated for interventional therapy.

Uniaxial strain/stress testing is not representative of the anisotropic behavior of the aneurysm wall in vivo. Although, bi-axial testing was contemplated in this study, it is technically challenging to carry out. In our experiments the main limitation was the small size of the strips ranging from 1.3 to $8 \mathrm{~mm}$. Work by (Toth et al., 2007) also confirms that bi-axial testing does not generate reliable and reproducible results. MacDonald and coauthors (MacDonald et al., 2000) investigated the molecular strength of the collagen fibers layers in four aneurysms. When comparing directional tissue strength, an anisotropy was demonstrated by a factor of two. In our study, aneurysm samples were selected in a meridional direction (which means for us the greater length of 
the sample and not a direction of anisotropy) in both groups demonstrating a difference between ruptured and unruptured aneurysms in this direction. A bi-axial testing of the sample may have addressed this high level of anisotropy, this was not possible due to physical limitations as mentioned above.

Furthermore, the probability of consistently and systematically slicing the aneurysm sample in the weakest direction in the ruptured aneurysms, and the strongest direction in unruptured aneurysms was unlikely.

The taking of measures of the size of samples such as the thickness and the width, was difficult to carry out because they are relatively irregular. We took average values, which can skew the estimation of the stresses and explain a higher dispersal of the values compared with those of strains. This also has consequences for the estimation of parameters $C_{1}$ and $C_{2}$ of the hyperelastic model.

Because of the small size of samples, in several cases the hypothesis of pure traction was not insured (the proportion of the length over the width was too low). This is an additional factor of error to be considered.

Aneurysm strips were fixed by glue on each extremity to aluminum grips. This procedure is delicate. It allows to block the sample on the grips, but can sometimes damage it when the glue is badly arranged and diffused in the sample, which is very small.

\section{Conclusion}

With a total of 39 analyzed aneurysms, our study confirms that ruptured aneurysms mainly present a soft tissue and unruptured aneurysms present a stiff material. But, contrary to what we observed in the previous study (Costalat et al. 2011), including only 16 samples, gender has no influence on material parameters. Aneurysmal tissues from males seem not to be stiffer than those of females and vice versa.

Secondly, the strain rupture limit is quite stable around $20 \%$ and seems not to be correlated with the status of the aneurysm (initially ruptured or unruptured), neither with the gender of the patient. However, stretch and stress rupture limit seems not to be independent on the rigidity. The existence of a fixed rupture limit for strain confirms that a soft tissue has a higher risk of rupture than a stiff one. That also confirms the observations suggesting that big aneurysms are dangerous.

Finally, from a mechanical point of view, consideration of the wall stiffness alone is not sufficient, the strain rupture limit must be taken into account too.

All these experimental results have to be considered carefully, a security coefficient should be applied on the bounded values.

Further studies investigating the biomechanical properties of cerebral aneurysms should be led to validate these observations and conclusions.

\section{Conflict of interest}

None declared

\section{References}

Asari S, Ohmoto T. Natural history and risk factors of unruptured cerebral aneurysms. Clin Neurol Neurosurg.;95:205-214, (1993)

Cebral J.R., Duan X., Chung B.J., Putman C., Aziz K. and Robertson A.M., Wall Mechanical Properties and Hemodynamics of Unruptured Intracranial Aneurysms, American Journal of Neuroradiology September, 36 (9) 1695-1703, (2015) 
Costalat V., et al., Biomechanical wall properties of human intracranial aneurysms resected following surgical clipping, Journal of Biomechanics, 44(15):2685 - 2691, (2011)

Duprey A., Trabelsi O., Vola M., Favre J.P., Avril S., Biaxial rupture properties of ascending thoracic aortic aneurysms, Acta Biomaterialia, Volume 42, Pages 273-285, ISSN 1742-7061, (2016)

Forsell C., Björck H.M., Eriksson P., Franco-Cereceda A., Gasser T.C., Biomechanical properties of the thoracic aneurysmal wall: differences between bicuspid aortic valve and tricuspid aortic valve patients, Ann. Thorac. Surg. 98, 65-71. (2014)

García-Herrera C.M., Atienza J.M., Rojo F.J., Claes E., Guinea G.V., Celentano D.J., García-Montero C., Burgos R.L., Mechanical behaviour and rupture of normal and pathological human ascending aortic wall, Med. Biol. Eng. Comput. 50, 559-566. (2012)

Holzapfel G.A., Ogden R.W. Biomechanical Modelling at the Molecular, Cellular and Tissue Levels. CISM Courses and Lectures, 508, Springer, Wien, New York pp. 259-343, (2009)

International Study of Unruptured Intracranial Aneurysms Investigators, Unruptured intracranial aneurysms--risk of rupture and risks of surgical intervention. International study of unruptured intracranial aneurysms investigators. N Engl J Med.;339:1725-1733, (1998)

Karmonik C, Diaz O, Grossman R, Klucznik R. In-vivo quantification of wall motion in cerebral aneurysms from $2 \mathrm{~d}$ cine phase contrast magnetic resonance images. Rofo.;182:140-150, (2010)

MacDonald DJ, Finlay HM, Canham PB. Directional wall strength in saccular brain aneurysms from polarized light microscopy. Ann Biomed Eng.;28:533-542, (2000)

Masson I, Fialaire-Legendre A, Godin C, Boutouyrie P, Bierling P, Zidi M., Mechanical properties of arteries cryopreserved at $-80{ }^{\circ} \mathrm{C}$ and $-150{ }^{\circ} \mathrm{C}$, Medical Engineering \& Physics. 31, 7, 825-832 (2009)

Pichamuthu J.E., Phillippi J.A., Cleary D.A., Chew D.W., Hempel J., Vorp D.A., Gleason T.G., Differential tensile strength and collagen composition in ascending aortic aneurysms by aortic valve phenotype, Ann. Thorac. Surg. 96, 2147-2154. (2013)

Pham T., Martin C., Elefteriades J., Sun W., Biomechanical characterization of ascending aortic aneurysm with concomitant bicuspid aortic valve and bovine aortic arch, Acta Biomater. 9, 7927-7936. (2013)

Robertson A. M. et al., Diversity in the Strength and Structure of Unruptured Cerebral Aneurysms, Annals of Biomedical Engineering, Volume 43, Issue 7, pp 1502-1515, (2015)

Sanchez M., Ambard D., Costalat V., Mendez S., Nicoud F., Jourdan F., Biomechanical assessment of the individual risk of rupture of intra cranial cerebral aneurysms: a proof of concept, Annals of Biomedical Engineering, Volume: 41, Issue: 1, Pages: 28-40, (2013).

Steiger H.J., Aaslid R., Keller, S. et al., Strength, elasticity and viscoelastic properties of cerebral aneurysms, Heart Vessels 5: 41. (1989)

Sluzewski M, Bosch JA, van Rooij WJ, Nijssen PC, Wijnalda D. Rupture of intracranial aneurysms during treatment with guglielmi detachable coils: Incidence, outcome, and risk factors. J Neurosurg.;94:238-240, (2001)

Toth BK, Nasztanovics F, Bojtar I. Laboratory tests for strength paramaters of brain aneurysms. Acta Bioeng Biomech.;9:3-7, (2007)

Valencia A. et al, Mechanical test of human cerebral aneurysm specimens obtained from surgical clipping, J. Mech. Med. Biol. 15, 1550075 (2015).

Wardlaw JM, White PM. The detection and management of unruptured intracranial aneurysms. Brain.;123 ( $\mathrm{Pt}$ 2):205-221, (2000)

Wiebers DO, Whisnant JP, Sundt TM, Jr., O'Fallon WM. The significance of unruptured intracranial saccular aneurysms. J Neurosurg.;66:23-29, (1987) 
Wiebers DO1, Whisnant JP, Huston J 3rd, Meissner I, Brown RD Jr, Piepgras DG, Forbes GS, Thielen K, Nichols D, O'Fallon WM, Peacock J, Jaeger L, Kassell NF, Kongable-Beckman GL, Torner JC; International Study of Unruptured Intracranial Aneurysms Investigators. Unruptured intracranial aneurysms: natural history, clinical outcome, and risks of surgical and endovascular treatment. Lancet;12:103-10, (2003) 


\begin{tabular}{|c|c|c|c|c|c|c|c|c|c|}
\hline $\begin{array}{c}\text { Specimen } \\
\text { number }\end{array}$ & Location & Risk Factors & Status & Gender & $\begin{array}{c}\text { Stress } \\
\text { rupture } \\
\text { limit }(\mathrm{MPa})\end{array}$ & $\begin{array}{l}\text { Stretch } \\
\text { rupture } \\
\text { limit }\end{array}$ & $\mathrm{C} 1$ (MPa) & $\mathrm{C} 2$ (MPa) & R2 \\
\hline 1 & ICA & 2 & $u$ & $\mathrm{~F}$ & 0,26 & 1,21 & 0,05 & 1,628 & 0,862 \\
\hline 2 & MCA & 0 & $\mathrm{R}$ & $\mathrm{F}$ & 0,6 & 1,26 & 0,16 & 2,55 & 0,868 \\
\hline 3 & PCA & 0 & $\mathrm{R}$ & $\mathrm{F}$ & 0,09 & 1,22 & 0,08 & 3,54 & 0,934 \\
\hline 4 & ACA & 2 & $\mathrm{U}$ & $\mathrm{F}$ & 0,8 & 1,3 & 0,015 & 2,46 & 0,915 \\
\hline 5 & MCA & 3 & $\mathrm{R}$ & $\mathrm{M}$ & 0,4 & 1,2 & 0,006 & 2,45 & 0,861 \\
\hline 6 & MCA & ? & $\mathrm{R}$ & $\mathrm{F}$ & 0,22 & 1,25 & 0,075 & 3,44 & 0,921 \\
\hline 7 & MCA & 3 & $\mathrm{U}$ & $\mathrm{F}$ & 0,16 & 1,26 & 0,127 & 5,19 & 0,969 \\
\hline 8 & MCA & 0 & $\mathrm{R}$ & $\mathrm{F}$ & 0,1 & 1,22 & 0,044 & 0,245 & 0,978 \\
\hline 9 & MCA & 2 & U-PRS & $F$ & 0,15 & 1,14 & 0,1 & 8,91 & 0,967 \\
\hline 10 & MCA & 1 & $\mathrm{R}$ & $\mathrm{M}$ & 0,25 & 1,18 & 0,04 & 2,62 & 0,891 \\
\hline 11 & ACA & 0 & U & $\mathrm{F}$ & 0,04 & 1,25 & 0,01 & 0,59 & 0,888 \\
\hline 12 & MCA & 0 & $\mathrm{U}$ & $\mathrm{M}$ & 0,25 & 1,25 & 0,25 & 5,54 & 0,955 \\
\hline 13 & MCA & 0 & $\mathrm{U}$ & $\mathrm{F}$ & 0,25 & 1,4 & 0,03 & 0,6 & 0,864 \\
\hline 14 & MCA & 0 & $\mathrm{U}$ & $\mathrm{M}$ & 0,14 & 1,18 & 0,02 & 0,01 & 0,917 \\
\hline 15 & ? & $?$ & $\mathrm{R}$ & $\mathrm{F}$ & 0,04 & 1,052 & 0,05 & 1,35 & 0,94 \\
\hline 16 & MCA & 3 & $\mathrm{U}$ & $\mathrm{F}$ & 0,3 & 1,2 & 0,08 & 4,3 & 0,945 \\
\hline 17 & ICA & 2 & U & $\mathrm{F}$ & 0,12 & 1,24 & 0,02 & 3 & 0,881 \\
\hline 18 & MCA & 2 & $\mathrm{R}$ & $\mathrm{M}$ & 0,25 & 1,2 & 0,08 & 2,68 & 0,917 \\
\hline 19 & $?$ & $?$ & $\mathrm{R}$ & $\mathrm{M}$ & 0,2 & 1,17 & 0,05 & 3,7 & 0,871 \\
\hline 20 & ? & ? & $\mathrm{U}$ & $\mathrm{F}$ & 0,3 & 1,16 & 0,09 & 5,3 & 0,952 \\
\hline 21 & ACA & 0 & U & $\mathrm{M}$ & 0,4 & 1,25 & 0,08 & 2,8 & 0,867 \\
\hline 22 & PICA & 0 & $\mathrm{R}$ & $\mathrm{F}$ & 0,2 & 1,1 & 0,15 & 7 & 0,915 \\
\hline 23 & MCA & 1 & $\mathrm{U}$ & $\mathrm{M}$ & 0,08 & 1,2 & 0,1 & 5,3 & 0,896 \\
\hline 24 & ACA & 1 & U & $\mathrm{F}$ & 0,5 & 1,3 & 0,015 & 1,6 & 0,86 \\
\hline 25 & ACA & 2 & $\mathrm{R}$ & $\mathrm{F}$ & 0,25 & 1,18 & 0,049 & 0,46 & 0,858 \\
\hline 26 & ACA & 1 & $\mathrm{R}$ & $\mathrm{M}$ & 0,35 & 1,15 & 0,1 & 2,76 & 0,865 \\
\hline 27 & PCA & 1 & U & $\mathrm{F}$ & 0,36 & 1,17 & 0,0576 & 3,8 & 0,853 \\
\hline 28 & ICA & 5 & $U$ & $\mathrm{~F}$ & 0,3 & 1,15 & 0,04 & 2,14 & 0,9 \\
\hline 29 & MCA & 5 & $U$ & $\mathrm{~F}$ & 0,3 & 1,17 & 0,074 & 2,36 & 0,916 \\
\hline 30 & ACA & 1 & $\mathrm{R}$ & $\mathrm{M}$ & 0,5 & 1,12 & 0,174 & 3,6 & 0,91 \\
\hline 31 & $\mathrm{MCA}$ & 2 & $\mathrm{U}$ & $\mathrm{M}$ & 1,2 & 1,15 & 0,29 & 11,6 & 0,854 \\
\hline 32 & MCA & 1 & $\mathrm{U}$ & $\mathrm{M}$ & 1,6 & 1,17 & 0,09 & 8,74 & 0,865 \\
\hline 33 & MCA & 5 & $U$ & $\mathrm{~F}$ & 0,3 & 1,08 & 0,25 & 15,77 & 0,91 \\
\hline 34 & MCA & 1 & $\mathrm{U}$ & $\mathrm{F}$ & 1 & 1,08 & 0,76 & 50,26 & 0,955 \\
\hline 35 & ICA & 1 & U-PRS & $\mathrm{F}$ & 0,18 & 1,25 & 0,038 & 0,377 & 0,888 \\
\hline 36 & MCA & 2 & $\mathrm{U}$ & $F$ & 0,65 & 1,2 & 0,036 & 2,13 & 0,947 \\
\hline 37 & MCA & 0 & $\mathrm{R}$ & $\mathrm{F}$ & 0,11 & 1,27 & 0,06 & 0,05 & 0,852 \\
\hline 38 & PCA & 5 & $\mathrm{R}$ & $\mathrm{F}$ & 0,35 & 1,32 & 0,06 & 1,5 & 0,95 \\
\hline 39 & MCA & 1 & $U$ & $\mathrm{~F}$ & 1,2 & 1,2 & 0,36 & 18,9 & 0,877 \\
\hline
\end{tabular}

Table 1: Summary of clinical, anatomical and biomechanical data of the 39 cases tested. (U=Unruptured, $R=R u p t u r e d, U$ $P R S=$ Unruptured with imminent pre-rupture symptoms, $M C A=$ Middle cerebral artery, $P C A=$ Posterior Communicant Artery, ICA = Internal Carotid Artery, PICA=Postero Inferior Cerebelar Artery, $C 1$ and $C 2$ are the Yeoh coefficients, $R 2=$ regression $R$ ) 

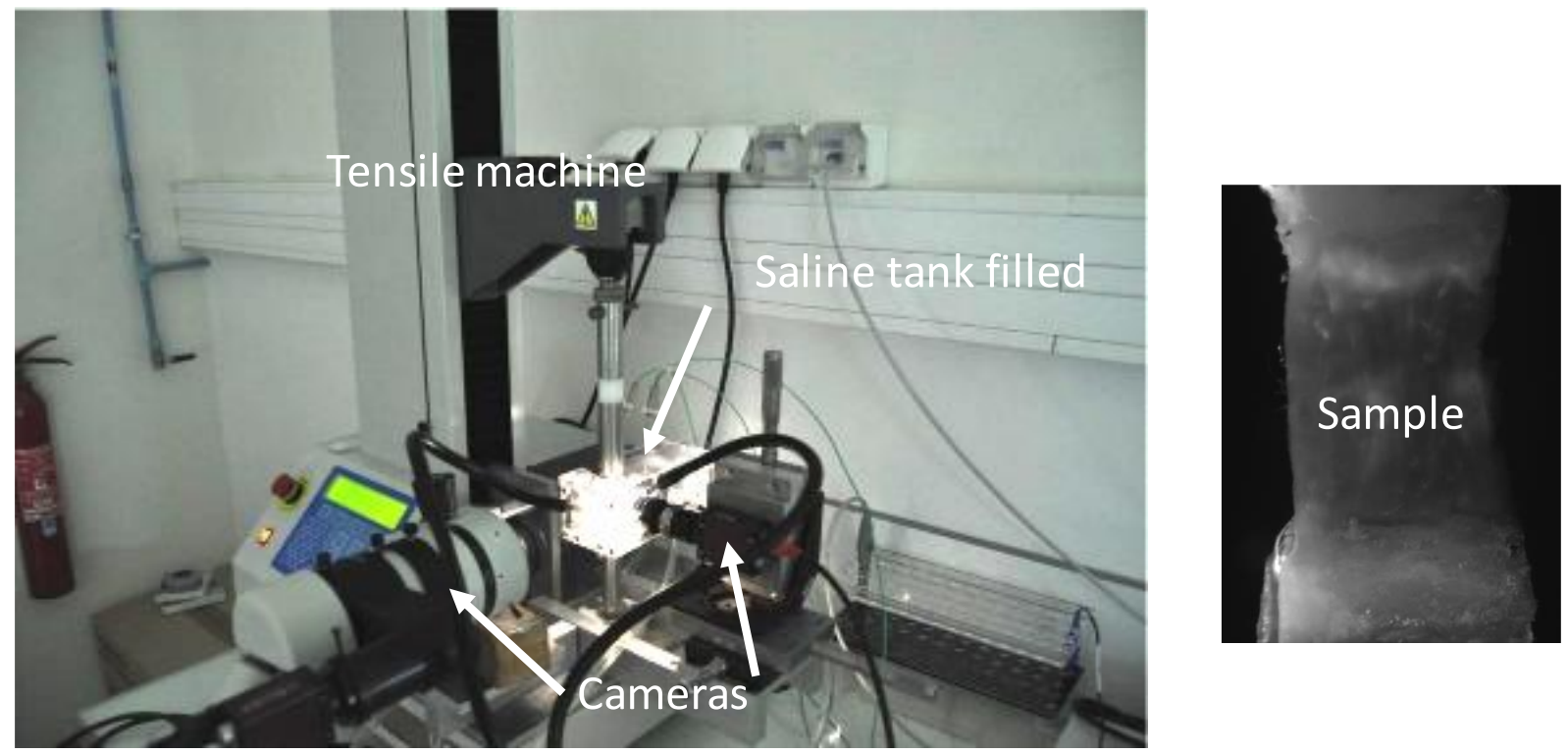

Figure 1 : Tensile test device

\section{Force/Displacement}

over load steps

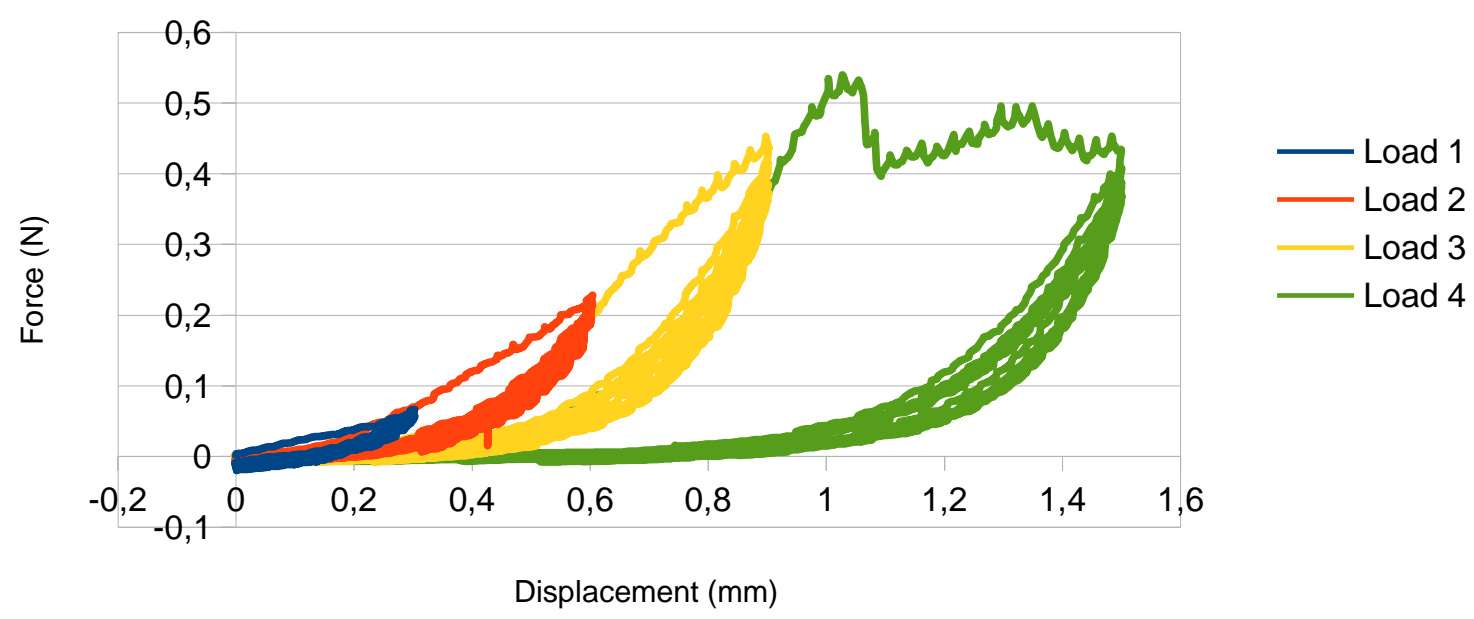

Figure 2 : Generic example of raw data from a uniaxial tensile test: Force/Displacement for different load steps 
HB8 Cycle 4

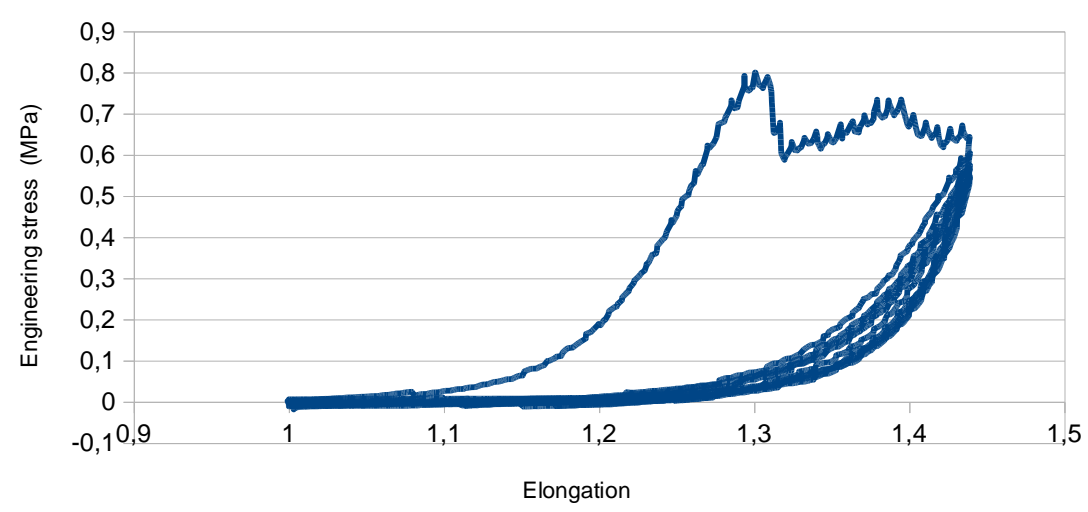

Figure 3 : Strain/stress curve showing the rupture limit

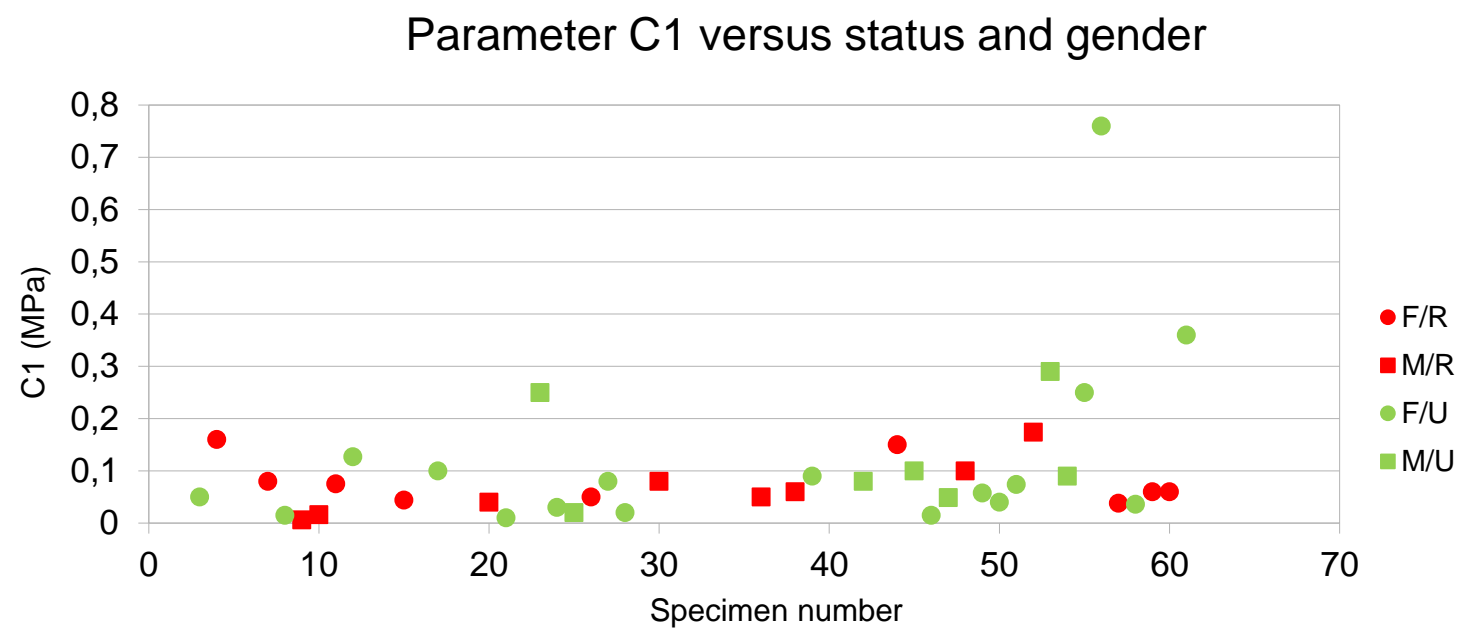

Figure 4: Material parameter C1 versus status (ruptured (red)/ unruptured (green)) and gender (female (circle)/ male (square)) of the aneurysm 


\section{Parameter $\mathrm{C} 2$ versus status and gender}

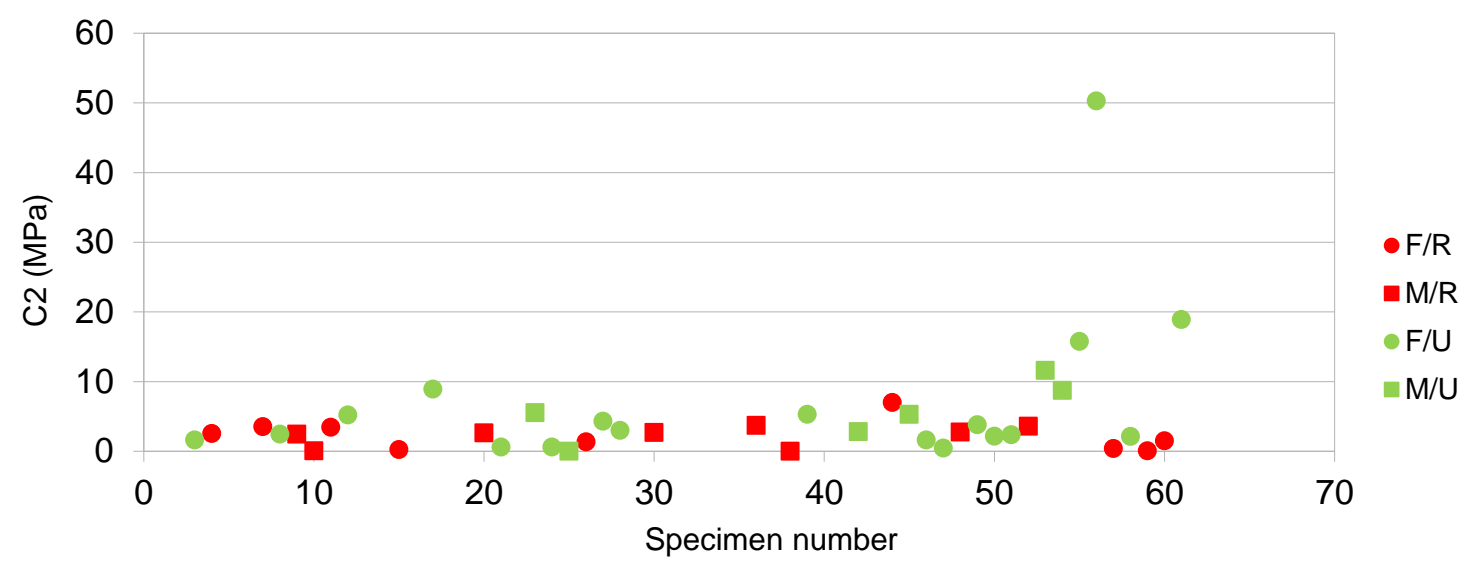

Figure 5: Material parameter C2 versus status (ruptured (red)/ unruptured (green)) and gender (female (circle)/ male (square)) of the aneurysm

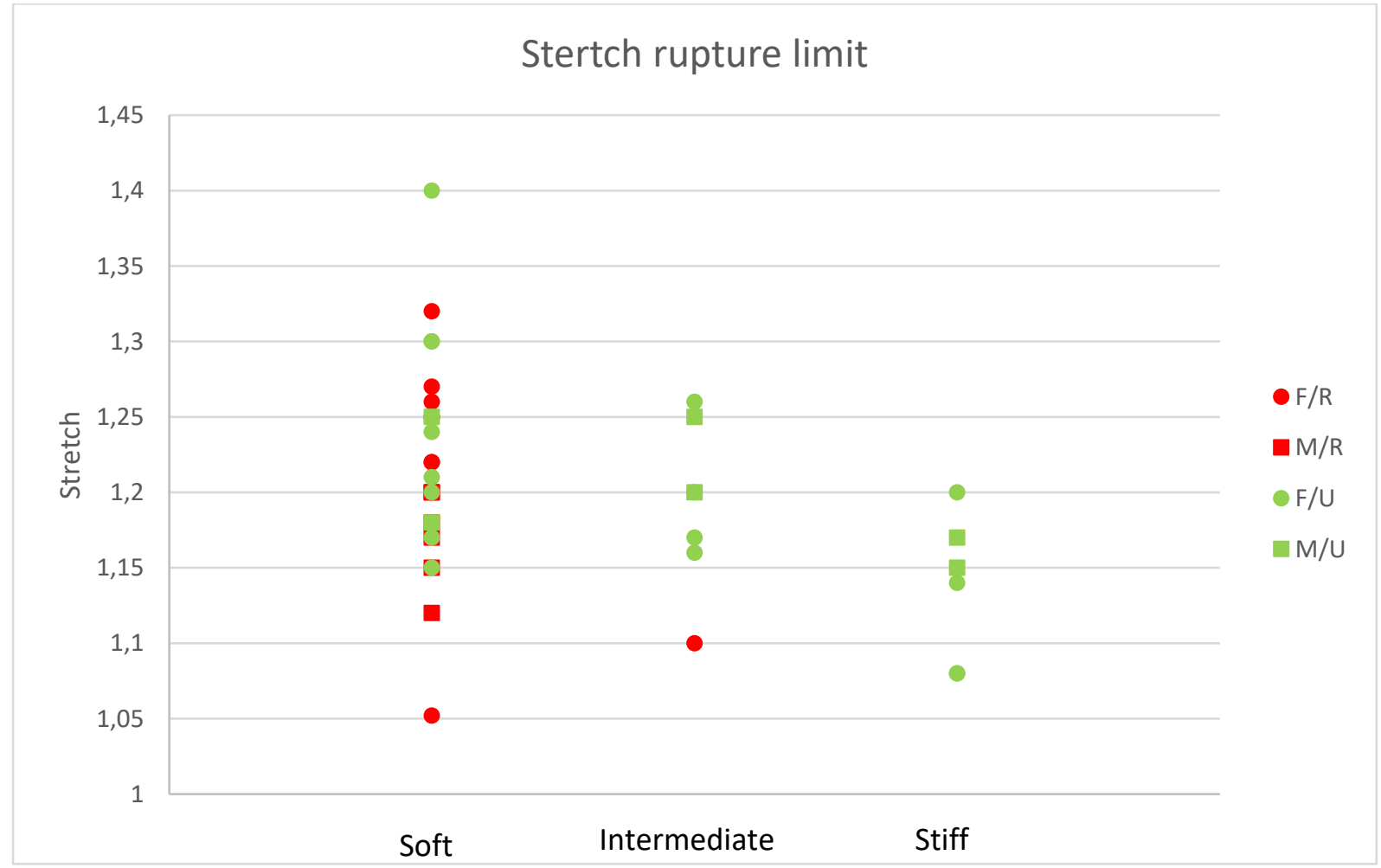

Figure 6: Stretch rupture limit versus status (ruptured (red)/ unruptured (green)), gender (female (circle)/ male (square)) and rigidity (soft/intermediate/stiff) of the aneurysm 


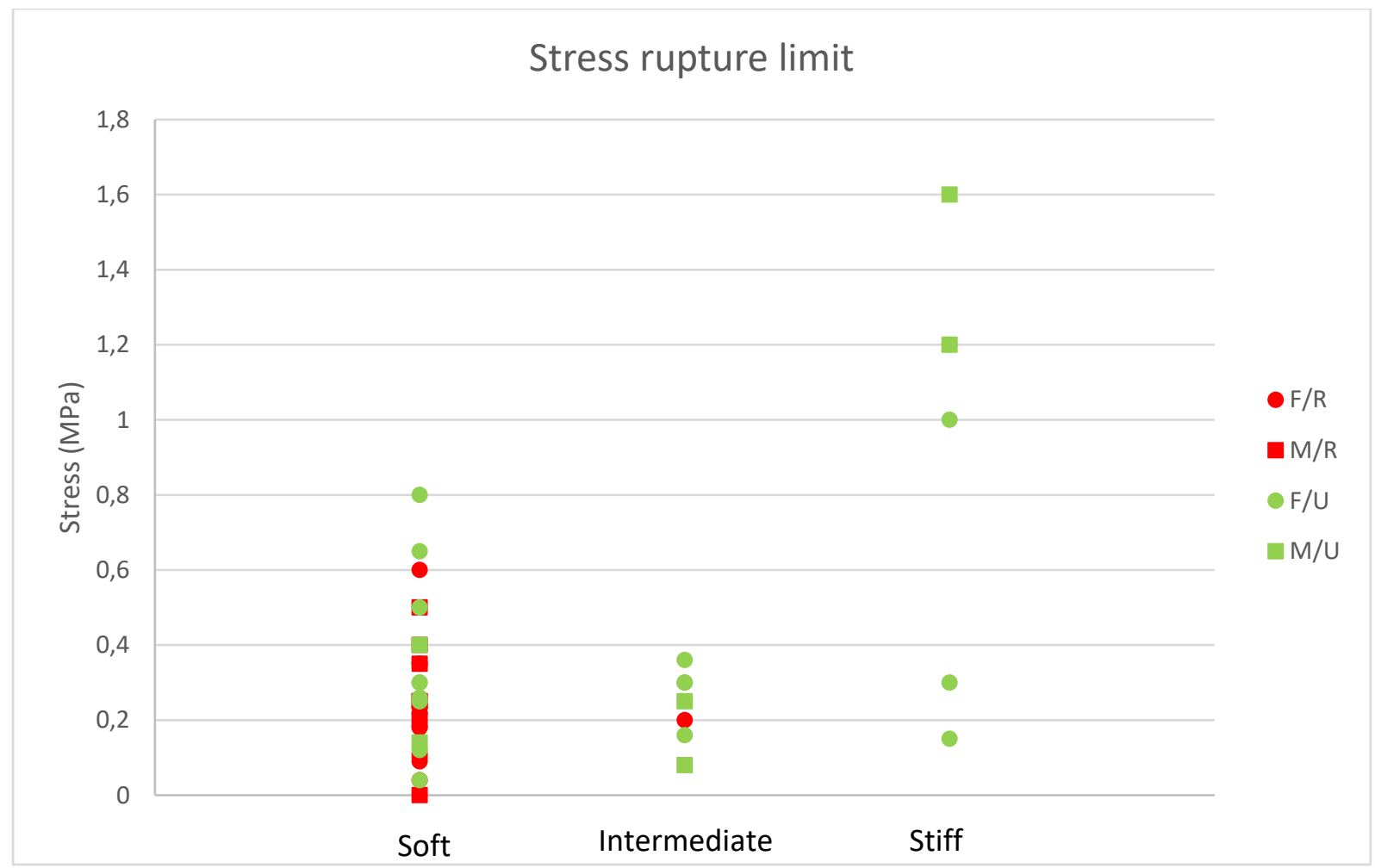

Figure 7: Stress (PK1) rupture limit versus status (ruptured (red)/ unruptured (green)), gender (female (circle)/ male (square)) and rigidity (soft/intermediate/stiff) of the aneurysm

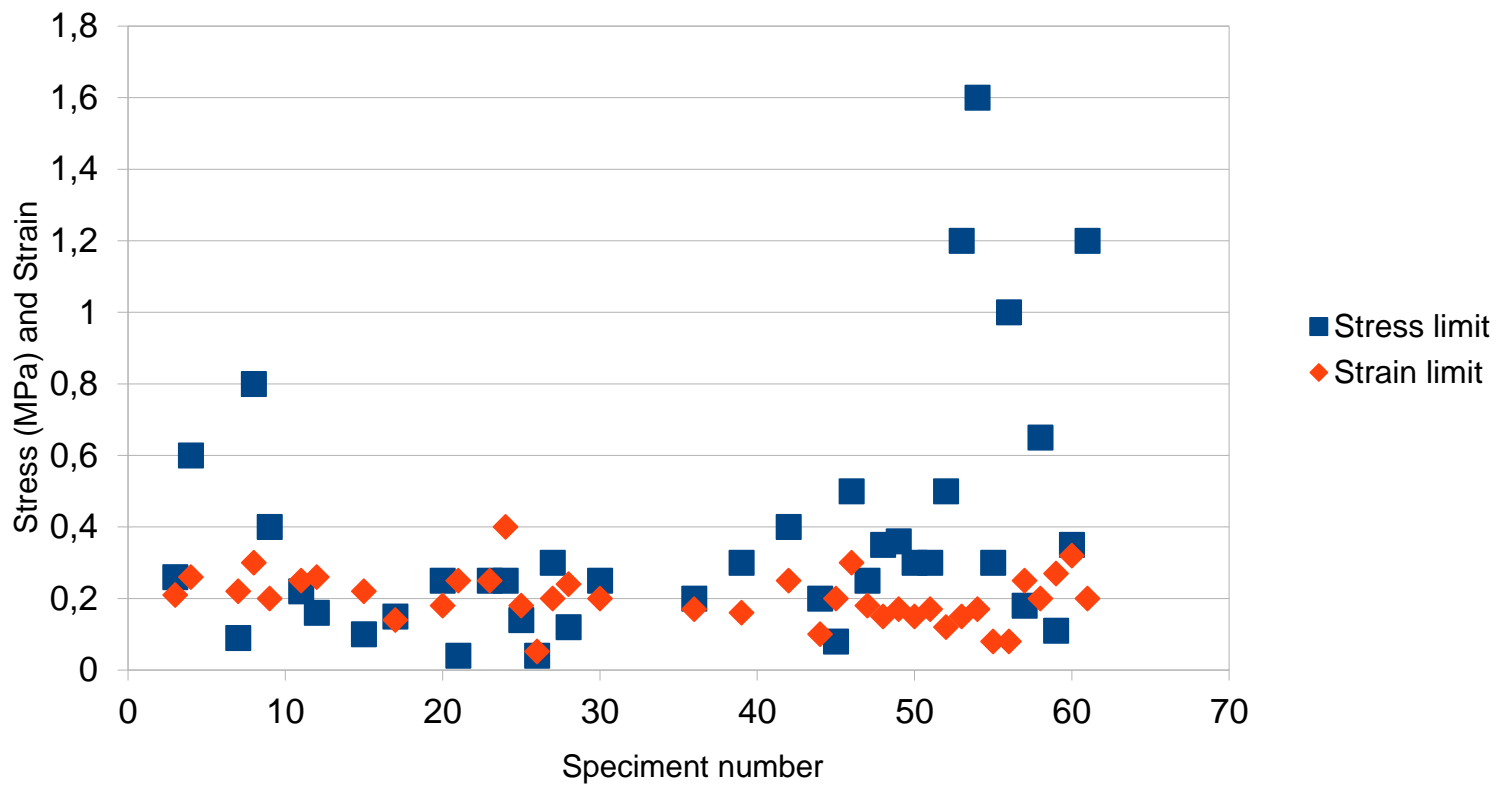

Figure 8 : Engineering stress $(M P a)$ and engineering strain limits gathered in the same graph 